\title{
Empirical correlation for ejector design
}

\author{
B.J. Huang*, J.M. Chang \\ Department of Mechanical Engineering, National Taiwan University, Taipei, Taiwan
}

Received 4 May 1998; received in revised form 24 November 1998; accepted 23 December 1998

\begin{abstract}
In the present study, two empirical correlations from the test results of 15 ejectors are derived for the performance prediction of ejectors using R $141 \mathrm{~b}$ as the working fluid. The ratio of the hypothetical throat area of the entrained flow to the nozzle throat area $A_{\mathrm{e}} / A_{\mathrm{t}}$, the geometric design parameter of the ejector $A_{3} / A_{\mathrm{t}}$, and the pressure ratios $P_{\mathrm{g}} / P_{\mathrm{e}}$ and $P_{\mathrm{c}} * / P_{\mathrm{e}}$ are used to correlate the performance of the ejector. The prediction of the entrainment ratio $\omega$ using the correlations is within $\pm 10 \%$ error. A method of calculation for the ejector design using the correlations is also developed. R141b is shown in the present study to be a good working fluid for an ejector. The measured $\omega$ for the ejectors used in the present study can reach as high as 0.54 at $P_{\mathrm{g}}=$ $0.465 \mathrm{MPa}\left(84^{\circ} \mathrm{C}\right), P_{\mathrm{c}}{ }^{*}=0.087 \mathrm{MPa}\left(28^{\circ} \mathrm{C}\right)$ and $P_{\mathrm{e}}=0.040 \mathrm{MPa}\left(8^{\circ} \mathrm{C}\right)$. For $P_{\mathrm{g}}=0.538 \mathrm{MPa}\left(90^{\circ} \mathrm{C}\right), P_{\mathrm{c}}{ }^{*}=0.101 \mathrm{MPa}\left(32^{\circ} \mathrm{C}\right)$ and $P_{\mathrm{e}}=0.040 \mathrm{MPa}\left(8^{\circ} \mathrm{C}\right), \omega$ reaches 0.45 . C) 1999 Elsevier Science Ltd and IIR. All rights reserved.
\end{abstract}

Keywords: Refrigerating system; Ejector system; Refrigerant; R141b; Ejector

\section{Corrélation empirique pour la conception des éjecteurs}

\section{Résumé}

Dans cette étude, on a établi deux corrélations empiriques à partir des résultats expérimentaux obtenus utilisant 15 éjecteurs; ces corrélations ont été utilisées ensuite pour prédire la performance d'éjecteurs utilisant le R141b comme fluide frigorigène. Les rapports $A_{e} / A_{t}$ (section de passage du fluide entraîné rapporté à la section théorique du col de l'éjecteur), et $A_{3} / A_{t}$ (section de sortie de l'éjecteur rapporté à la section théorique du col de l'éjecteur) et les relations entre pressions $P_{g} / P_{e}$ et $P_{c} * / P_{e}$ sont utilisés pour trouver la corrélation de la performance de l'éjecteur. La prévision du taux d'entraînement à partir des corrélations est précise à la hauteur de $\pm 10 \%$. Les auteurs ont également développé une méthode de calcul permettant de concevoir des éjecteurs à partir des corrélations. On a montré dans cette étude que le R141b s'avère être un fluide actif efficace pour cette utilisation. Le $\omega$ mesuré des éjecteurs utilisés dans cette étude peuvent atteindre 0.54 à $P_{g}=0.465 \mathrm{MPa}\left(84^{\circ} \mathrm{C}\right)$, $P_{c}^{*}=0.087 \mathrm{MPa}\left(28^{\circ} \mathrm{C}\right)$ et $P_{e}=0.040 \mathrm{MPa}\left(8^{\circ} \mathrm{C}\right)$. Pour $P_{g}=0.538 \mathrm{MPa}\left(90^{\circ} \mathrm{C}\right), P_{c}^{*}=0.101 \mathrm{MPa}\left(32^{\circ} \mathrm{C}\right)$ et $P_{e}=0.040 \mathrm{MPa}$ $\left(8^{\circ} \mathrm{C}\right)$, $\omega$ atteint 0.45. (C) 1999 Elsevier Science Ltd and IIR. All rights reserved.

Mots clés: Système frigorifique; Système à éjecteur; Frigorigène; R141b; Ejecteur

\section{Nomenclature}

A area, $\mathrm{m}^{2}$

* Corresponding author. Tel.: + 886-2-2363-4790; fax: + 8862-2363-0549.

E-mail address: bjhuang@tpts6.seed.net.tw (B.J. Huang) $d \quad$ diameter, $\mathrm{m}$

$G \quad$ mass flow rate per unit area, $\mathrm{kg} \mathrm{s}^{-1} \mathrm{~m}^{-2}$

$h \quad$ enthalpy, $\mathrm{kJ} \mathrm{kg}^{-1}$

$\dot{m} \quad$ mass flow rate, $\mathrm{kg} \mathrm{s}^{-1}$

$P \quad$ pressure, $\mathrm{MPa}$

$T \quad$ temperature, ${ }^{\circ} \mathrm{C}$

$v \quad$ specific volume of gas, $\mathrm{m}^{3} \mathrm{~kg}^{-1}$ 
$V \quad$ gas velocity, $\mathrm{m} \mathrm{s}^{-1}$

$x \quad$ nozzle position, $\mathrm{m}$

$y \quad$ position of the hypothetical throat superscripts

* critical condition of ejector subscripts

c exit of ejector; condenser

co limiting condition of ejector operational mode

e inlet port of the entrained flow; hypothetical throat

g nozzle inlet

$\mathrm{p}$ primary flow

p1 nozzle exit

s suction or entrained flow

t nozzle throat

$1 \quad$ nozzle exit

2 entrance of the constant-area mixing chamber

3 exit of the constant-area mixing chamber

\section{Introduction}

Since its invention in the early twentieth century, the gasto-gas, or vapor-to-vapor ejector, has found wide application in industries for the processes of evacuation, refrigeration, and solid powder transportation etc., or in modern jet planes for thrust augmentation. Air and steam are the common working fluids of an ejector. The study of refrigerant (CFCs, HCFCs and HFCs) ejectors for air-conditioning or refrigeration applications started in the mid-1950s for utilizing low-grade energy such as solar or waste heat energy as the heat source.

The operation of a gas-to-gas or vapor-to-vapor ejector results mainly from the gas-dynamic effect and the momentum exchange of two gaseous streams (primary and second- ary or entrained streams) inside the ejector. Two choking phenomena exist in the ejector performance [1]: one in the primary flow through the nozzle and the other in the entrained or suction flow. The entrained flow rate or the entrainment ratio (entrained-to-primary flow ratio $\omega=$ $\dot{m}_{\mathrm{s}} / \dot{m}_{\mathrm{p}}$ ) of an ejector is affected by many factors. The physical phenomena involve supersonic flow, shock interactions, and turbulent mixing of two streams inside the ejector enclosure. It is so complicated that the design of an ejector to date still heavily relies on trials-and-errors methods although a number of gas-dynamic theories for ejector analysis were developed by several researchers [2-4].

In the present study, we experimentally derive a set of correlations for ejector performance. The present study also indicates that R141b is a good working fluid for an ejector.

\section{Experimental setup}

\subsection{Test facility and operation}

Fig. 1 shows the schematic diagram of the test facility. $\mathrm{R} 141 \mathrm{~b}$ is selected as the working fluid in the present study since R141b has a positive-slope saturated-vapor line in the thermodynamic $T$-s diagram. This will not produce condensation of the vapor during an isentropic expansion in the ejector, and thus reduces losses.

The working fluid is heated and evaporated in the generator by the circulated glycol which is heated by a $5-\mathrm{kW}$ electrical heater installed in the heating tank. The glycol temperature is controlled to within $\pm 0.5 \mathrm{~K}$ accuracy by a PID controller so that the primary flow of the ejector from the generator is maintained at fixed temperature. The condenser is cooled by a direct expansion of liquid R22

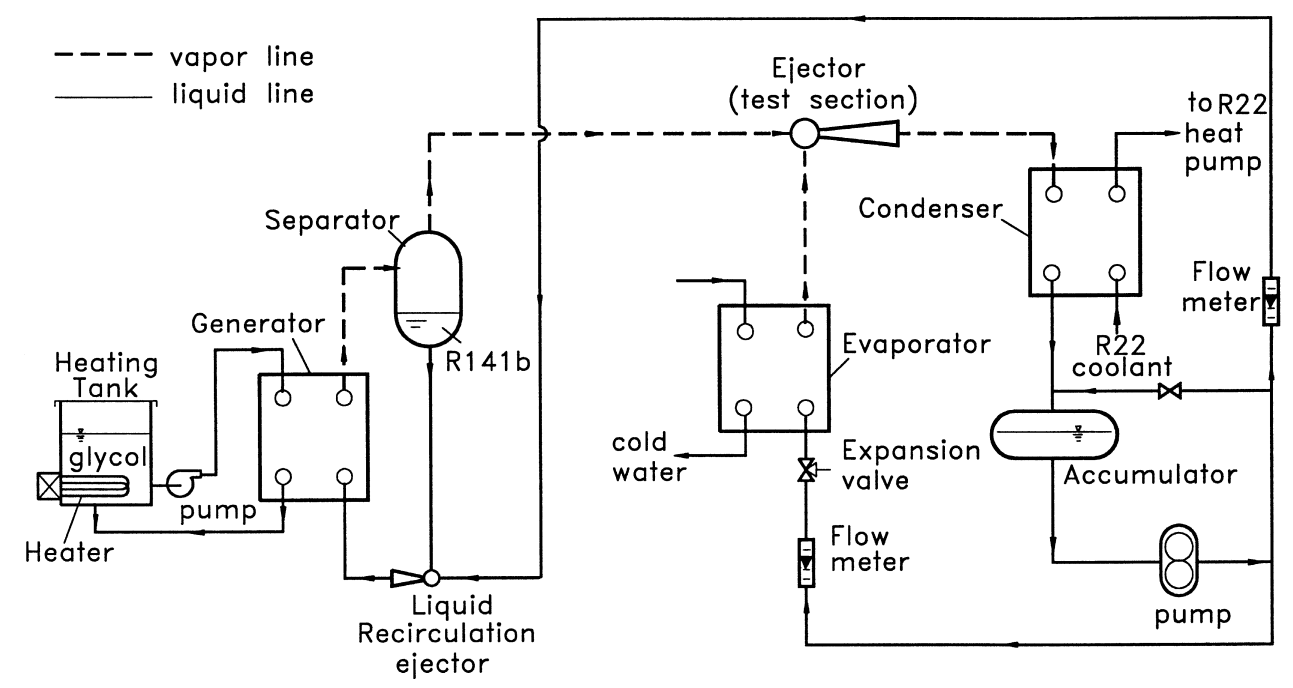

Fig. 1. Schematic diagram of ejector test facility.

Fig. 1. Schéma du dispositif utilisé pour tester des éjecteurs. 


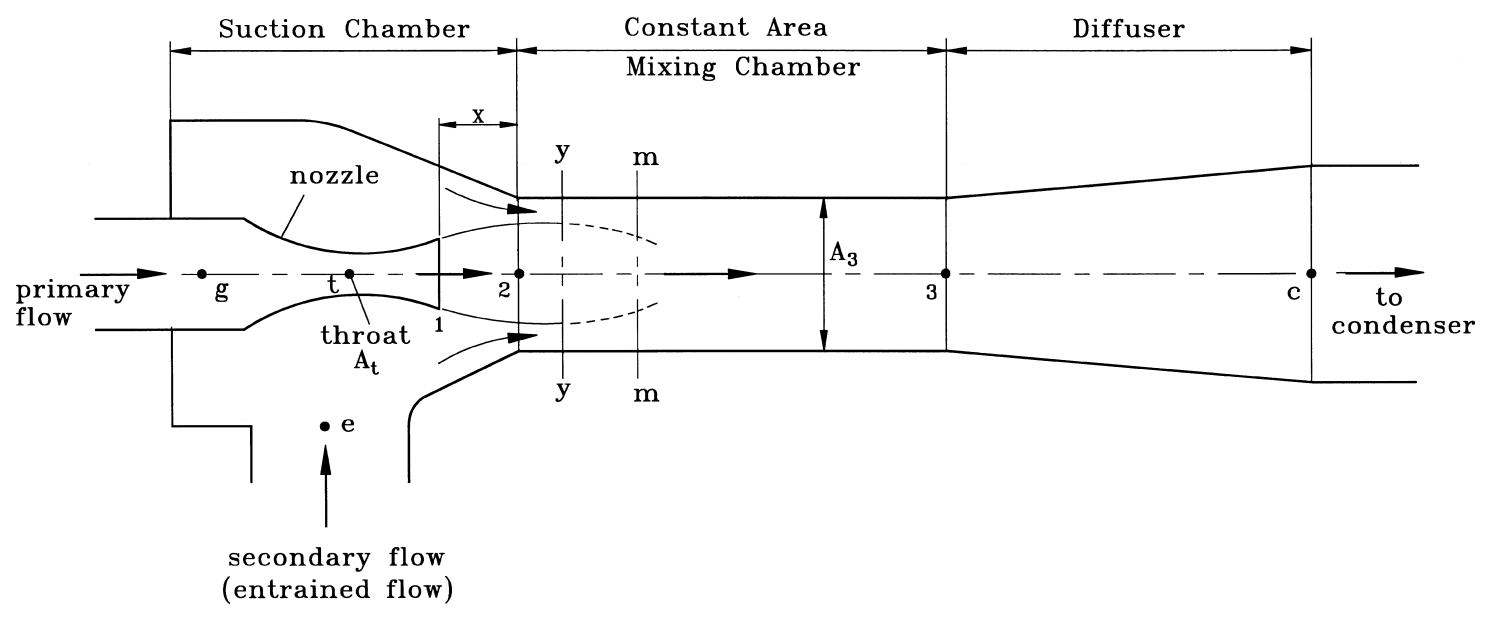

Fig. 2. Schematic diagram of ejector design.

Fig. 2. Schéma de la conception de l'éjecteur.

refrigerant generated from a heat pump using a vapor compression cycle. The condenser temperature, as well as the back pressure of the ejector can thus be adjusted between $10^{\circ} \mathrm{C}$ and $30^{\circ} \mathrm{C}$ and the experiment can be performed in any season. Cold water circulates through the evaporator to remove the evaporation heat.

The mass flow rate of the primary and the entrained flows is measured using two rotameters which are calibrated to within $\pm 5 \%$ uncertainty. The primary flow is determined from the mass balance of the ejector. The mass flow rate through the nozzle of the ejector can also be calculated from the choked flow relation in gas-dynamics using the measured inlet temperature and pressure, and the properties of R141b. It was found that the calculated value coincides with the measured one to within $\pm 5 \%$ uncertainty.

Three strain-gage type pressure transducers are used to measure the pressures of the primary and entrained flows, and the back pressure. The uncertainty is within $\pm 5 \%$. Vapor temperatures at the nozzle inlet, the suction port and the exit port of the ejector are measured by T-type thermocouples with an uncertainty of $\pm 0.7 \mathrm{~K}$.

The temperature and pressure signals are recorded by a YOKOGAWA hybrid recorder HR1300. All the measured data are transferred to a PC586 through a IEEE488 interface for data processing.

Table 1

Dimensions of nozzles

Tableau 1

Dimensions des tuyères

\begin{tabular}{lll}
\hline Nozzle & Throat diameter, $d_{\mathrm{t}>}(\mathrm{mm})$ & Exit diameter, $d_{\mathrm{p} 1}(\mathrm{~mm})$ \\
\hline A & 2.64 & 4.50 \\
B & 2.75 & 4.66 \\
D & 2.93 & 4.46 \\
\hline
\end{tabular}

To obtain a steady-state operation during the test, the flow rates of the R22 coolant flow for the condenser, the cold water for the evaporator and the glycol solution are kept steady. To adjust the flow rate to the generator, we installed a bypass line at the exit of the circulation pump. It takes about $1 \mathrm{~h}$ to warm up the test facility and about $30 \mathrm{~min}$ for each steady-state run.

\subsection{Ejector specifications}

Fig. 2 is the schematic diagram of an ejector. To derive an empirical correlation for ejector performance, we have to test as many different ejectors as possible. The ejector is thus designed in three major parts: nozzle, suction chamber body, and constant-area mixing chamber (with diffuser). The connection between the different parts is to standard specifications so that the parts are interchangeable. Three nozzles are designed and fabricated in the experiment. The specifications of nozzles are listed in Table 1. We designed five different sizes of the constant-area mixing chambers (including diffuser) as listed in Table 2. The ejector area

Table 2

Dimensions of constant-area mixing chambers

Tableau 2

Dimensions des chambres des mélange à superficie constante

\begin{tabular}{llll}
\hline $\begin{array}{l}\text { Mixing } \\
\text { chamber }\end{array}$ & $d_{3}(\mathrm{~mm})$ & $\begin{array}{l}\text { Inlet converging } \\
\text { angle }\left({ }^{\circ}\right)\end{array}$ & $\begin{array}{l}\text { Ejector area ratio (with } \\
\text { Nozzle A), } A_{3} / A_{\mathrm{t}}\end{array}$ \\
\hline $\mathrm{A}$ & 6.70 & 68 & 6.441 \\
$\mathrm{~B}$ & 6.98 & 60 & 6.990 \\
$\mathrm{G}$ & 7.34 & 60 & 7.730 \\
$\mathrm{C}$ & 7.60 & 67 & 8.287 \\
$\mathrm{D}$ & 8.10 & 68 & 9.414 \\
\hline
\end{tabular}




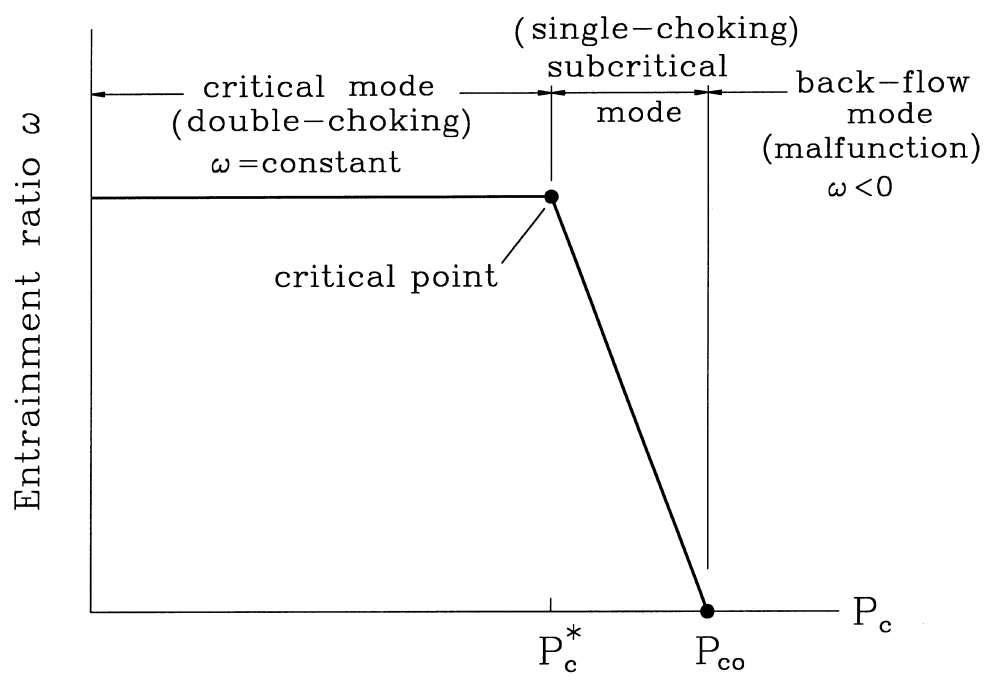

Fig. 3. Operational modes of an ejector.

Fig. 3. Modes de fonctionnement d'un éjecteur.

ratios provided for the tests thus range from 6.4 to 9.4 if combined with Nozzle A.

\section{Experimental analysis of R141b ejector}

\subsection{Performance modes of an ejector}

In addition to the choking in the nozzle, the ejector has another choking phenomenon. As pointed out by Huang et al. [1], the second choking of an ejector results from the acceleration of the entrained flow from a stagnant state at the suction port to a supersonic flow in the mixing chamber. Fig. 3 shows the variation of entrainment ratio $\omega$ with discharge or back pressure $P_{\mathrm{c}}$ at fixed suction pressure $P_{\mathrm{e}}$ and fixed primary flow pressure $P_{\mathrm{g}}$.

The ejector performance can then be divided into three operational modes, according to the back pressure $P_{\mathrm{c}}$ (referring to Fig. 3): (1) double-choking or critical mode at $P_{\mathrm{c}} \leq$ $P^{*}$, while the primary and the entrained flows are both

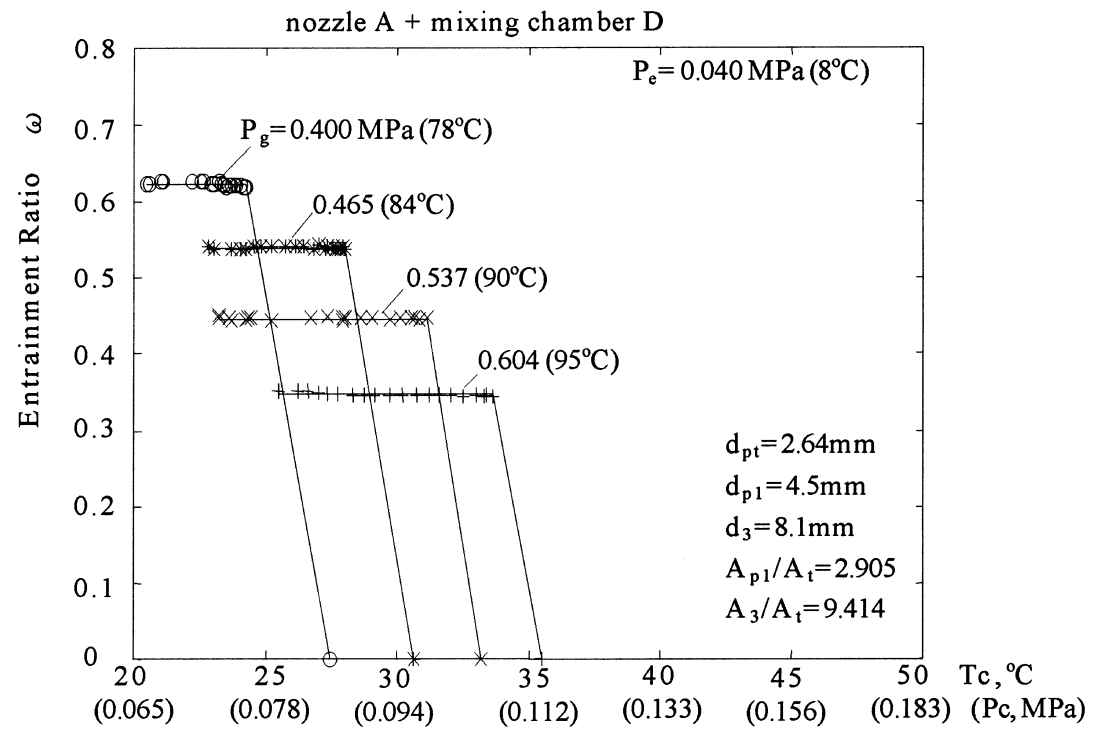

Fig. 4. Entrainment ratio measurement for Ejector A-D.

Fig. 4. Mesures de la relation d'entraînement pour l'éjecteur A-D. 


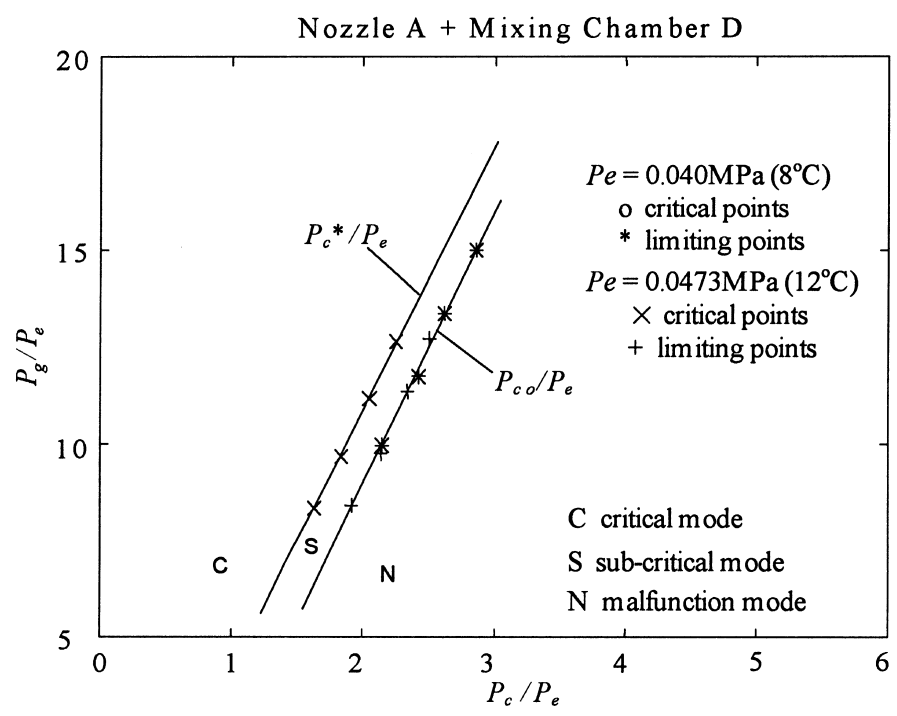

Fig. 5. Measured operation mode for Ejector A-D.

Fig. 5. Mode de fonctionnement (mesures) de l'éjecteur A-D.

choking and the entrainment ratio is constant, i.e. $\omega=$ constant; (2) single-choking or subcritical mode at $P^{*_{\mathrm{c}}}<$ $P_{\mathrm{c}}<P_{\mathrm{c}}$, while only the primary flow is choking and $\omega$ changes with the back pressure $P_{\mathrm{c}}$; and (3) back-flow or malfunction mode at $P_{\mathrm{c}} \leq P_{\mathrm{co}}$, while both the primary and the secondary flows are not choking and the entrained flow is reversed (malfunction), i.e. $\omega \leq 0$.

The performance mode of an ejector depends on the ejector design and the operating conditions. The operational mode essentially results from the shock movement inside the ejector [1]. For better performance of an ejector cooling system, the ejector should be designed and operated in the double-choking or critical mode whose performance characteristics are our main interest in the present study. The critical mode is determined by the critical back pressure $P^{*}$, which is related to the pressures of the primary and the entrained flows and the design of the ejector. Hence, $P *_{\mathrm{c}}$ is an important variable in an ejector's performance.

The aforementioned ejector performance can be illustrated by the entrainment ratio measured for the ejector assembly of Nozzle A and Mixing Chamber D (Ejector AD), as shown in Fig. 4. For easy understanding in an airconditioning application, we also present the saturated vapor temperature in the figures throughout this article.

Fig. 5 shows that the operational modes of Ejector AD can be characterized using the pressure ratios, $P_{\mathrm{g}} / P_{\mathrm{e}}$, $P_{\mathrm{c}} / P_{\mathrm{e}}$ and $P_{\mathrm{co}} / P_{\mathrm{e}}$. For the same typical ejector, the correlation between $P_{\mathrm{g}} / P_{\mathrm{e}}$ and $P^{*}{ }_{\mathrm{c}} / P_{\mathrm{e}}$ or $P_{\mathrm{co}} / P_{\mathrm{e}}$ exists, irrespective of the operation conditions, as shown in Fig. 5. However, the functional relationship changes for different ejectors. That is, a universal correlation cannot be obtained simply from the functional relation of $P_{\mathrm{g}} / P_{\mathrm{e}}$ and $P_{\mathrm{c}} /$
$P_{\mathrm{e}}$ or $P_{\mathrm{co}} / P_{\mathrm{e}}$. In the present study, we use the hypothetical throat area of the entrained flow in the critical mode as a key variable for deriving a universal correlation for ejector performance.

\subsection{Hypothetical throat area of entrained flow at critical mode operation}

As choking of the entrained flow results from the acceleration of the entrained flow from a stagnant state at the suction port to a supersonic flow in the mixing chamber. A hypothetical throat area, "effective area $A_{\mathrm{e}}$ " [1,5], can be defined for the entrained flow at critical operation mode. The hypothetical throat area of an ejector $A_{\mathrm{e}}$ can be determined from the measured mass flow rate of the entrained flow $\dot{m}_{s}$.

Fig. 2 shows the schematic of the mixing process of the two streams in the ejector. It is postulated [1,3] that after exhausting from the nozzle, the primary flow fans out without mixing with the entrained flow and induces a converging duct for the entrained flow. This duct acts as a converging nozzle such that the entrained flow is accelerated to a sonic velocity at some cross-section $y y$ (hypothetical throat). After that, mixing of the two streams starts. The position of the hypothetical throat (cross-section $y y$ ) can be either in the suction chamber or in the constant-area mixing chamber depending on the nozzle position, i.e. the distance $x$ from the constant-area mixing chamber. The present study found experimentally that the ejector with a nozzle located inside the suction chamber has a better performance. 


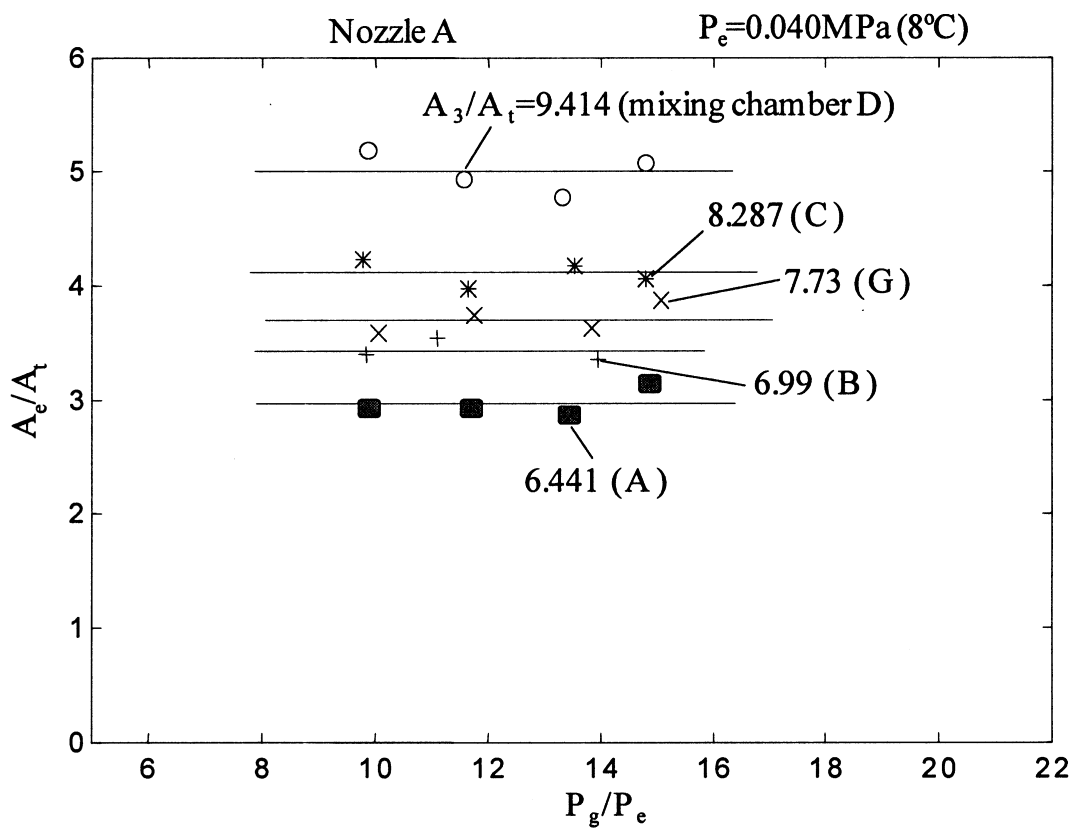

Fig. 6. Variation of hypothetical throat area ratio with $P_{\mathrm{g}} / P_{\mathrm{e}}$ for various ejectors at $P_{\mathrm{e}}=0.040 \mathrm{MPa}$.

Fig. 6. Variation du rapport $A_{3} / A_{\mathrm{t}}$ en fonction de $P_{\mathrm{g}} / P_{\mathrm{e}}$ pour divers éjecteurs à $P_{\mathrm{e}}=0.040 \mathrm{MPa}$.

\subsection{Calculation of hypothetical throat area $A_{e}$}

The computation of $A_{\mathrm{e}}$ is carried out using an iterative scheme and a thermodynamic table to take into account the real gas properties of R141b. For given inlet conditions $\left(P_{\mathrm{e}}\right.$, $\left.T_{\mathrm{e}}\right)$ at the suction port, the computational procedures are as follows:

1. Given a pressure at the hypothetical throat $P_{\mathrm{y}}$, find the enthalpy at the hypothetical throat for an isentropic process from the thermodynamic table $h_{\mathrm{ys}}=\left(S_{\mathrm{e}}, P_{\mathrm{y}}\right)$, where $S_{\mathrm{e}}=f\left(P_{\mathrm{e}}, T_{\mathrm{e}}\right)$.

2. Compute the gas velocity at the hypothetical throat from the energy balance relation

$V_{\mathrm{y}}=\sqrt{2 \eta_{\mathrm{s}}\left(h_{\mathrm{e}}-h_{\mathrm{ys}}\right)}$

where $\eta_{\mathrm{s}}=\left(h_{\mathrm{e}}-h_{\mathrm{y}}\right) /\left(h_{\mathrm{e}}-h_{\mathrm{ys}}\right)$ is the isentropic efficiency of the entrained flow. Here, we take $\eta_{\mathrm{s}}=0.85$.

3. Compute the enthalpy at the hypothetical throat for an adiabatic process using the energy balance relation

$h_{\mathrm{y}}=h_{\mathrm{e}}-V_{\mathrm{y}}^{2} / 2$.

4. Find the specific volume of gas at the hypothetical throat from the thermodynamic table

$v_{\mathrm{y}}=v\left(P_{\mathrm{y}}, h_{\mathrm{y}}\right)$

5. Compute the mass flow rate per unit area at the hypothetical throat $G_{y}$

$$
G_{\mathrm{y}}=\frac{\dot{m}_{\mathrm{s}}}{A_{\mathrm{e}}}=\frac{V_{\mathrm{y}}}{v_{\mathrm{y}}} .
$$

6. Return to Step (1) and change the pressure at the hypothetical throat $P_{\mathrm{y}}$. Repeat the above computation until $G_{\mathrm{y}}$ reaches a maximum value (a choking condition).

7. Compute the hypothetical throat area $A_{\mathrm{e}}$ using the measured entrained flow rate $\dot{m}_{\mathrm{s}}$ from the relation

$$
A_{\mathrm{e}}=\dot{m}_{\mathrm{s}} / G_{\mathrm{y}} .
$$

\subsection{Performance function of R141b ejector}

The hypothetical throat area of an ejector $A_{\mathrm{e}}$ can be treated as a characteristic parameter of the ejector. The entrained flow rate of an ejector can be easily determined if $A_{\mathrm{e}}$ is known for a given suction condition. Further, we can use the area ratio $A_{\mathrm{e}} / A_{\mathrm{t}}$ to represent the entrainment ratio of an ejector $\omega$.

Combining the correlation shown in Fig. 5, we found that the entrainment ratio $\omega$ of an ejector in the critical mode operation is a function of ejector design (represented by the area ratio $\left.A_{3} / A_{\mathrm{t}}\right)$, and the pressure ratios $\left(P_{\mathrm{g}} / P_{\mathrm{e}}\right.$ and $\left.P^{*}{ }_{\mathrm{c}} / P_{\mathrm{e}}\right)$. That is, the following correlation exists for the ejector performance

$$
\frac{A_{\mathrm{e}}}{A_{\mathrm{t}}}=f\left(\frac{A_{3}}{A_{\mathrm{t}}}, \frac{P_{\mathrm{g}}}{P_{\mathrm{e}}}, \frac{P_{\mathrm{c}}^{*}}{P_{\mathrm{e}}}\right) .
$$




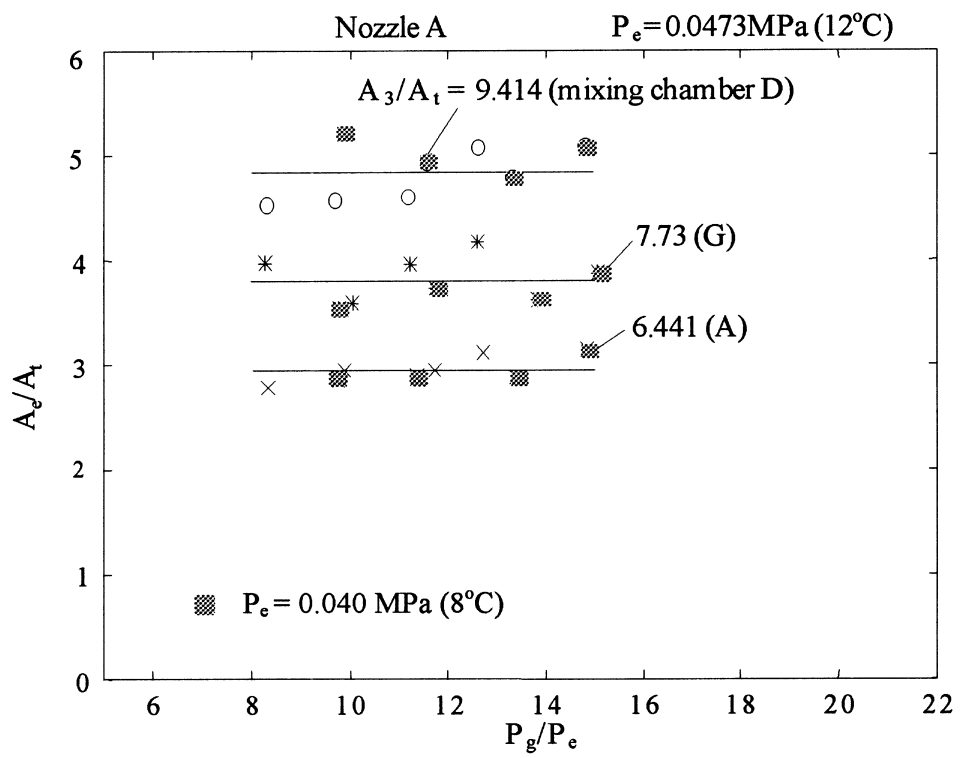

Fig. 7. Variation of hypothetical throat area ratio with $P_{\mathrm{g}} / P_{\mathrm{e}}$ for various ejectors at $P_{\mathrm{e}}=0.0473 \mathrm{MPa}$.

Fig. 7. Variation du rapport $A_{3} / A_{\mathrm{t}}$ en fonction de $P_{\mathrm{g}} / P_{\mathrm{e}}$ pour divers éjecteurs à $P_{\mathrm{e}}=0.0473 \mathrm{MPa}$.

\subsection{Empirical correlations of R141b ejector}

In the present study, we tested five different ejectors (Ejector A-A, A-B, A-C, A-D, A-G) at different $P_{\mathrm{g}}$ corresponding to the saturated vapor temperature from $78^{\circ} \mathrm{C}$ to $95^{\circ} \mathrm{C}$ which is in the application range. It is very interesting to note from Figs. 6 and 7 that, the hypothetical area ratio $A_{\mathrm{e}} / A_{\mathrm{t}}$ is approximately independent of $P_{\mathrm{g}} / P_{\mathrm{e}}$. The value of $A_{\mathrm{e}} / A_{\mathrm{t}}$ depends on the ejector design $\left(A_{3} / A_{\mathrm{t}}\right)$. Plotting $A_{\mathrm{e}} / A_{\mathrm{t}}$ versus $A_{3} / A_{\mathrm{t}}$, we found that $A_{\mathrm{e}} / A_{\mathrm{t}}$ is approximately

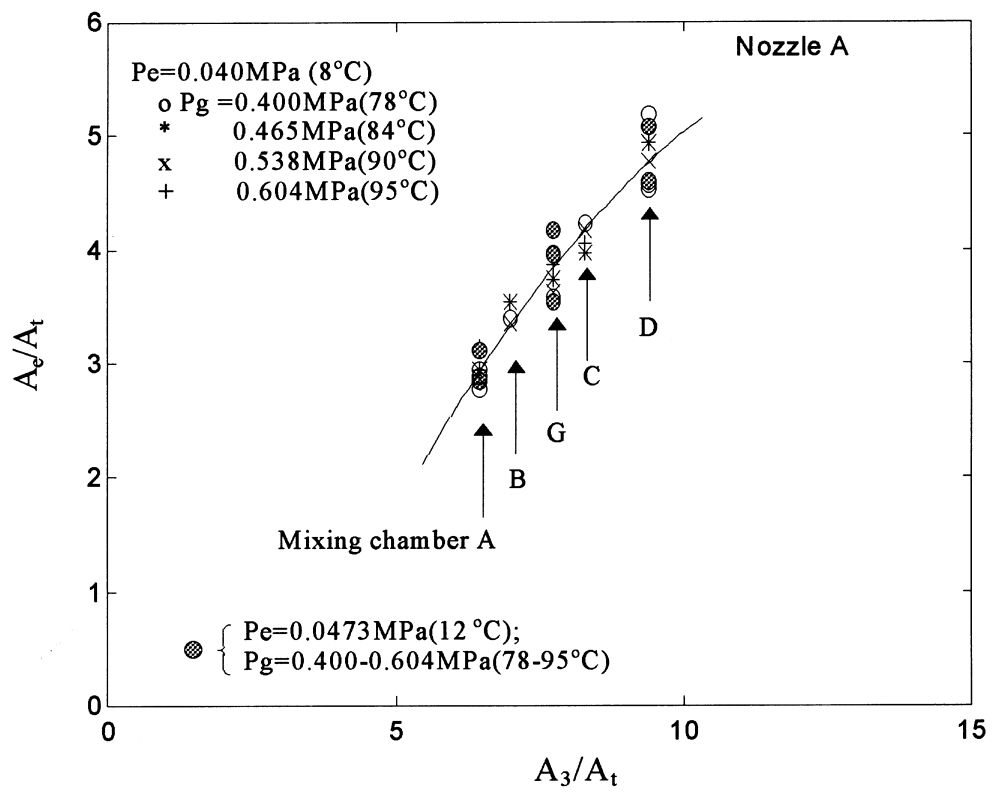

Fig. 8. Variation of hypothetical throat area ratio with ejector area ratio $A_{3} / A_{\mathrm{t}}$.

Fig. 8. Variation du rapport $A_{3} / A_{\mathrm{t}}$. 


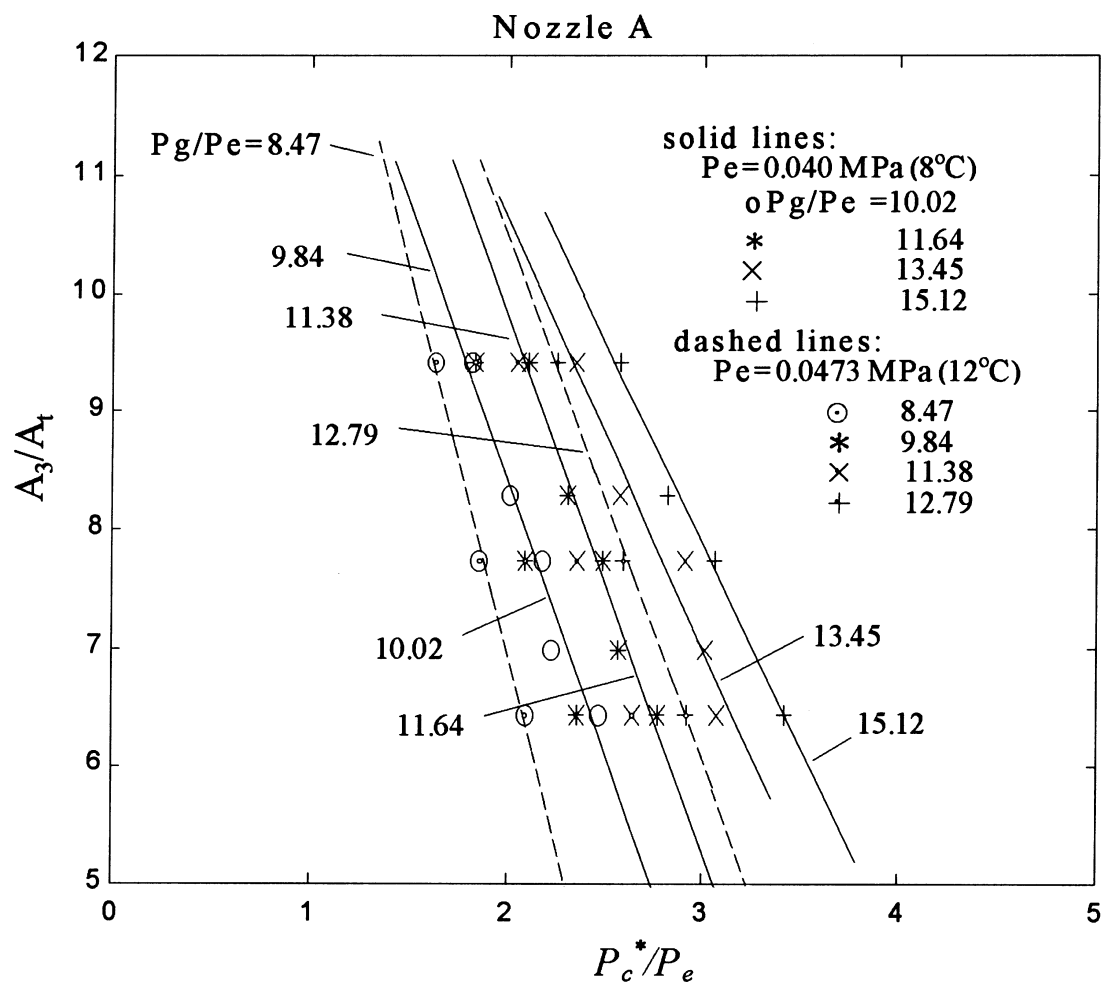

Fig. 9. Variation of ejector design area ratio $A_{3} / A_{\mathrm{t}}$ with pressure ratios $P_{\mathrm{g}} / P_{\mathrm{e}}$ and $P^{*}{ }_{\mathrm{c}} / P_{\mathrm{e}}$.

Fig. 9. Variations des relations des superficies d'éjecteurs $A_{3} / A_{\mathrm{t}}$ en fonction des relations $P_{\mathrm{g}} / P_{\mathrm{e}}$ et $P^{*}{ }_{\mathrm{c}} / P_{\mathrm{e}}$.

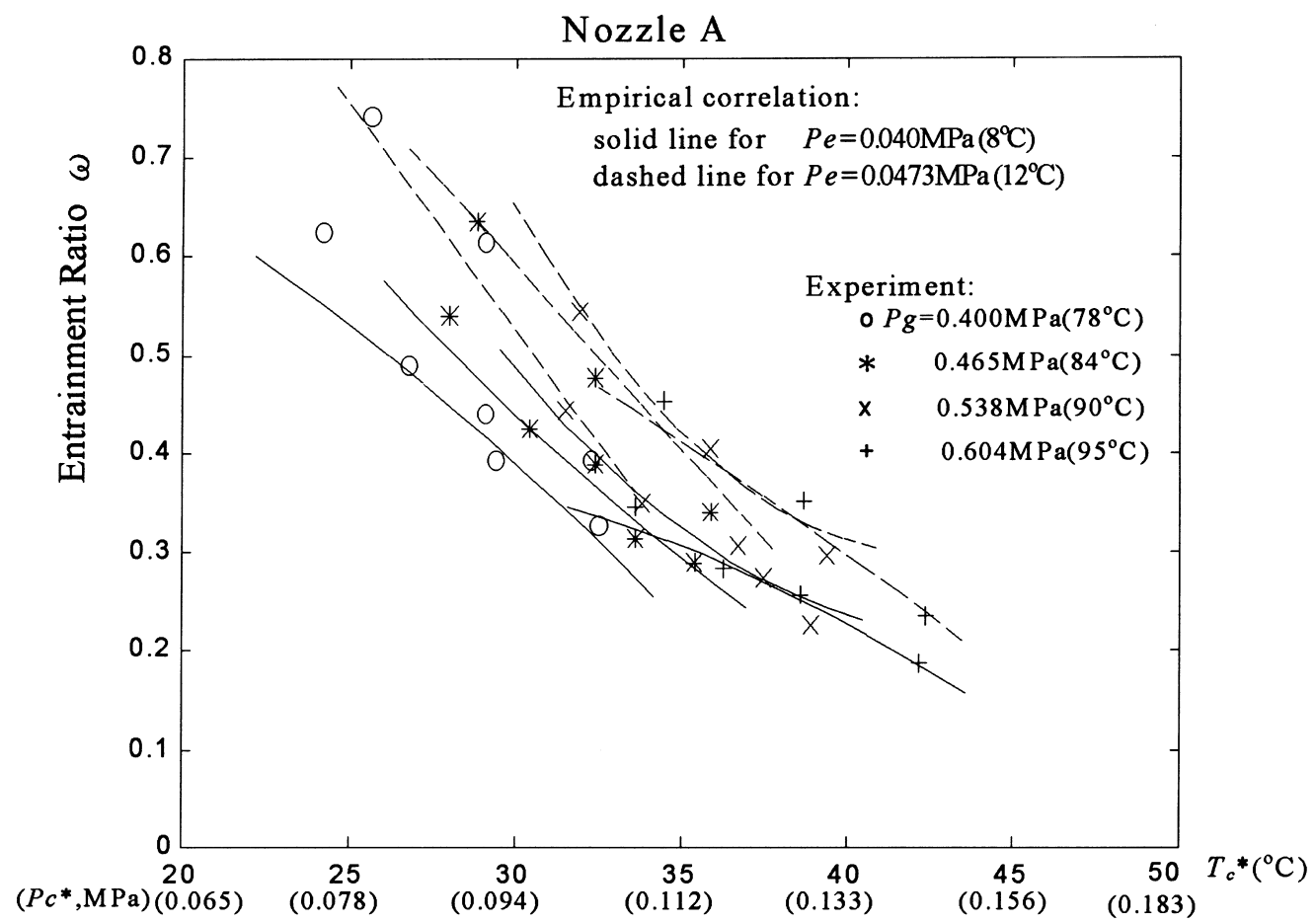

Fig. 10. Comparison of measured and calculated $\omega$.

Fig. 10. Comparaison des $\omega$ mesurés et calculés. 


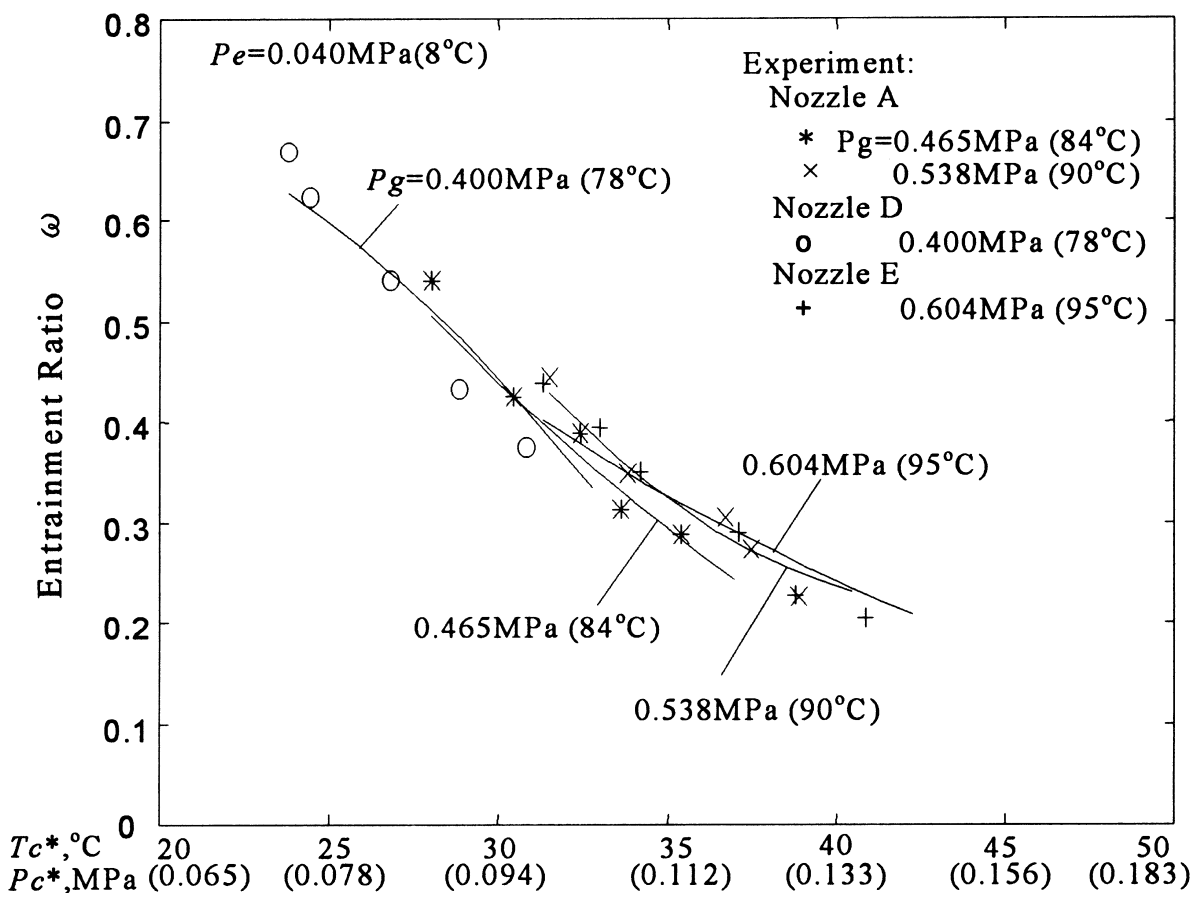

Fig. 11. Comparison of measured and calculated $\omega$ from extrapolation of the empirical correlations.

Fig. 11. Comparaison des $\omega$ mesurés et calculés à partir d'extrapolations des corrélations empiriques.

a function of $A_{3} / A_{\mathrm{t}}$ only as shown in Fig. 8. An empirical correlation can then be obtained:

$\frac{A_{\mathrm{e}}}{A_{\mathrm{t}}}=-0.0517\left(\frac{A_{3}}{A_{\mathrm{t}}}\right)^{2}+1.4362\left(\frac{A_{3}}{A_{\mathrm{t}}}\right)-4.1734$.

From the above relationship, the performance function of an ejector, Eq. (6), can be simplified to

$\frac{A_{3}}{A_{\mathrm{t}}}=f\left(\frac{P_{\mathrm{g}}}{P_{\mathrm{e}}}, \frac{P^{*}{ }_{\mathrm{c}}}{P_{\mathrm{e}}}\right)$

Eq. (8) indicates that, for a fixed ejector $\left(A_{3} / A_{\mathrm{t}}\right.$ fixed $)$, the ejector performance follows the relationship:

$f\left(\frac{P_{\mathrm{g}}}{P_{\mathrm{e}}}, \frac{P^{*} \mathrm{c}}{P_{\mathrm{e}}}\right)=$ constant

which was shown to exist in practice, as shown in Fig. 5.

The test results for five different ejectors are plotted in Fig. 9 from which another empirical correlation can be determined as

$$
\begin{aligned}
\frac{A_{3}}{A_{\mathrm{t}}}= & b_{o}+b_{1} r_{\mathrm{c}}+b_{2} r_{\mathrm{c}}^{2}+b_{3} r_{\mathrm{g}}+b_{4} r_{\mathrm{c}} r_{\mathrm{g}}+b_{5} r_{\mathrm{c}}^{2} r_{\mathrm{g}}+b_{6} r_{\mathrm{g}}^{2} \\
& +b_{7} r_{\mathrm{c}} r_{\mathrm{g}}^{2}+b_{8} r_{\mathrm{c}}^{2} r_{\mathrm{g}}^{2}
\end{aligned}
$$

where $\quad r_{\mathrm{c}}=P^{*}{ }_{\mathrm{c}} / P_{\mathrm{e}} ; \quad r_{\mathrm{g}}=P_{\mathrm{g}} / P_{\mathrm{e}} ; \quad b_{\mathrm{o}}=5.4497$; $b_{1}=-6.7759 ; \quad b_{2}=1.4952 ; b_{3}=2.3116 ; b_{4}=-0.590$; $b_{5}=0.018105 ; \quad b_{6}=-0.03786 ; \quad b_{7}=0.012983 ; \quad b_{8}=$ -0.000812145 .
Eqs. (7) and (10) are the two empirical correlations for an R141b ejector's performance. A comparison between the measured and the calculation using the correlation for the five tested ejectors is presented in Fig. 10. The errors are all within $\pm 10 \%$.

The above empirical correlations can also be extrapolated to predict the performance of ejector with different nozzles. We tested another 10 different ejectors, which were assembled from two different nozzles (Nozzle D and Nozzle E) and five constant-area mixing chambers (A, B, C, D, G). The tests results are compared with the calculations using the empirical correlations. Fig. 11 shows that the errors are all within $\pm 10 \%$. This further verifies the empirical correlations for the performance prediction of ejectors using $\mathrm{R} 141 \mathrm{~b}$ as the working fluid.

\section{Application of empirical correlations in ejector design}

The two empirical correlations for R141b ejector performance, Eqs. (7) and (10), are very useful in the design application. The procedure of ejector design analysis is as follows:

1. Given the operating conditions: $P_{\mathrm{g}}, T_{\mathrm{g}}, P_{\mathrm{e}}, T_{\mathrm{e}}, P^{*}{ }_{\mathrm{c}}, T^{*}{ }_{\mathrm{c}}$.

2. Determine the ejector area ratio $A_{3} / A_{\mathrm{t}}$ from Eq. (10).

3. Determine the hypothetical area ratio $A_{\mathrm{e}} / A_{\mathrm{t}}$ from Eq. (7).

4. Compute the mass flow rate per unit area $G_{\mathrm{y}}\left(=\dot{m}_{\mathrm{s}} / A_{\mathrm{e}}\right)$ through the hypothetical throat of the entrained flow 
following the calculating procedures outlined in the first five steps which are presented with Eqs. (1)(4).

5. Repeat Step 4 to calculate the mass flow rate per unit area $G_{\mathrm{t}}\left(=\dot{m}_{\mathrm{p}} / A_{\mathrm{t}}\right)$ through the nozzle throat of the primary flow.

6. Calculate the entrainment ratio $\omega$ from the relation

$$
\omega \equiv \frac{\dot{m}_{\mathrm{s}}}{\dot{m}_{\mathrm{p}}}=\frac{\dot{m}_{\mathrm{s}}}{A_{\mathrm{e}}} \times \frac{A_{\mathrm{t}}}{\dot{m}_{\mathrm{p}}} \times \frac{A_{\mathrm{e}}}{A_{\mathrm{t}}}=\frac{G_{\mathrm{y}}}{G_{\mathrm{t}}} \times \frac{A_{\mathrm{e}}}{A_{\mathrm{t}}} .
$$

\section{Discussion}

In the present study, we have derived two empirical correlations for the prediction of R141b ejector performance. The correlations can result in a prediction error $< \pm 10 \%$ However, it should be noted that the performance of an ejector is also affected by the quality of hardware machining, such as finishing, interior surface roughness, centerline alignment, and the material used. The empirical correlations were derived from the test results of 15 ejectors with good quality in machining.

The ejector area ratio depends on the ratio of back pressure to entrained pressure $P{ }_{\mathrm{c}} / P_{\mathrm{e}}$ (compression ratio) and also the refrigerant used. The area ratios of the ejectors used in the present experiments range from 6.4 to 9.4 which is adequate for $141 \mathrm{~b}$ only. As can be seen from Fig. 9, the compression ratio decreases with increasing ejector area ratio. For the area ratio ranging from 6.4 to 9.4 , the compression ratio is in the range of $1.5-3.5$, which is the operating range of air-conditioning systems.

Superheating of the primary flow may improve the ejector performance, as was noted by several researchers. However, we did not superheat the primary flow and still obtained a high entrainment ratio. This is due to the fact that $\mathrm{R} 141 \mathrm{~b}$ has a positive-slope saturated-vapor line in the thermodynamic $T-S$ diagram and the vapor will not condense during an isentropic expansion in the ejector.

For example, for Ejector A-D, the measured entrainment ratio $\omega \approx 0.54$ at $P_{\mathrm{g}}=0.465 \mathrm{MPa}\left(84^{\circ} \mathrm{C}\right), P^{*}{ }_{\mathrm{c}}=$ $0.087 \mathrm{MPa}\left(28^{\circ} \mathrm{C}\right)$ and $P_{\mathrm{e}}=0.040 \mathrm{MPa}\left(8^{\circ} \mathrm{C}\right)$ as shown in Fig. 10. For $P_{\mathrm{g}}=0.538 \mathrm{MPa}\left(90^{\circ} \mathrm{C}\right), \quad P^{*}{ }_{\mathrm{c}}=$ $0.101 \mathrm{MPa}\left(32^{\circ} \mathrm{C}\right)$ and $P_{\mathrm{e}}=0.040 \mathrm{MPa}\left(8^{\circ} \mathrm{C}\right)$, the measured entrainment ratio $\omega \approx 0.45$.

This also indicates that R141b is a very good working fluid for an ejector as was found by Dorantes and Lallemand [6]. Although R123 has a similar boiling point to R141b, the performance of an R123 ejector is worse according to theoretical calculation [7].

The application of a refrigerant ejector in refrigeration and air-conditioning is not as successful as a steam or air ejector because of its poor performance compared with that of a conventional device. However, we have shown that the ejector performance can be further improved through careful design and good manufacturing technique. Further studies are still underway in order to develop an ejector cooling system with high COP. A preliminary experiment [8] shows that the COP of an ejector cooling system can be as high as 0.50 at $T_{\mathrm{g}}=84^{\circ} \mathrm{C}, T^{*}{ }_{\mathrm{c}}=28^{\circ} \mathrm{C}$, and $T_{\mathrm{e}}=8^{\circ} \mathrm{C}$.

\section{Conclusion}

In the present study, we derived two empirical correlations from the test results of 15 ejectors for the performance prediction of ejectors using R141b as the working fluid. The ratio of the hypothetical throat area of the entrained flow to the nozzle throat area $A_{\mathrm{e}} / A_{\mathrm{t}}$, the geometric design parameter of the ejector $A_{3} / A_{\mathrm{t}}$, and the pressure $\operatorname{ratios} P_{\mathrm{g}} / P_{\mathrm{e}}$ and $P_{\mathrm{c}}{ }_{\mathrm{c}} / P_{\mathrm{e}}$ are used to correlate the performance of the ejector. The prediction of the entrainment ratio $\omega$ using the correlations is within $\pm 10 \%$ error. A method of calculation for the ejector design using the present correlations is also presented. In addition, $\mathrm{R} 141 \mathrm{~b}$ is shown to be a good working fluid for an ejector. The measured $\omega$ for the ejectors used in the present study can reach as high as 0.54 at $P_{\mathrm{g}}=0.465 \mathrm{MPa}\left(84^{\circ} \mathrm{C}\right), P_{\mathrm{c}}^{*}=$ $0.087 \mathrm{MPa}\left(28^{\circ} \mathrm{C}\right)$ and $P_{\mathrm{e}}=0.040 \mathrm{MPa}\left(8^{\circ} \mathrm{C}\right)$. For $P_{\mathrm{g}}=0.538 \mathrm{MPa}\left(90^{\circ} \mathrm{C}\right), \quad P^{*}{ }_{\mathrm{c}}=0.101 \mathrm{MPa}\left(32^{\circ} \mathrm{C}\right) \quad$ and $P_{\mathrm{e}}=0.040 \mathrm{MPa}\left(8^{\circ} \mathrm{C}\right), \omega$ reaches 0.45 .

\section{Acknowledgements}

The present study was supported by the National Science Council, ROC, Taiwan, through Grant No. NSC86-2811-E002-004R.

\section{References}

[1] Huang BJ, Jiang CB, Fu FL. Ejector performance characteristics and design analysis of jet refrigeration system. ASME J. Engng Gas Turbines and Power 1985;107:792-802.

[2] Sun D-W. Recent developments in the design theories and applications of ejectors-a review. J. Inst. Energy 1995;68:65-79.

[3] Sun D-W. Variable geometry ejectors and their applications in ejector refrigeration systems. Energy 1996;21:919-929.

[4] Sun D-W. Experimental investigation of the performance characteristics of a steam jet refrigeration system. Energy Sources 1997;19:349-367.

[5] Munday JT, Bagster DF. A new ejector theory applied to steam jet refrigeration. Ind. Engng Chem. Process Des. Dev. 1977;16(4):442-449.

[6] Dorantes R, Lallemand A. Prediction of performance of a jet cooling system operating with pure refrigerants or non-azeotropic mixtures. Int. J. Refrig. 1995;18(1):21-30.

[7] Sun D-W, Emes IW. Performance characteristics of HCFC-123 ejector refrigeration cycles. Int. J. Energy Res. 1996;20:871885.

[8] Huang BJ, Petrenko VA, Chang JM, Zhuk KB. A high-performance solar ejector cooling system. Proceedings ISES 1997 Solar World Congress. Tajeon, Korea, 24-30 August 1997, Vol. 4, pp. 274-277. 